\title{
Coastal armoring and sinking property values: the case of seawalls in California
}

\author{
Arlan Brucal ${ }^{1}[$. John Lynham²
}

Received: 10 September 2019 / Accepted: 4 May 2020 / Published online: 4 June 2020

(c) The Author(s) 2020

\begin{abstract}
Rising sea levels necessitate careful consideration of different forms of coastal protection but cost-benefit analysis is limited when important non-market social costs have not been measured. Seawalls protect individual properties but can potentially impose negative externalities on neighboring properties via accelerated beach loss. We conduct a hedonic valuation of seawalls in two coastal California counties: San Diego and Santa Cruz. We find no strong evidence to suggest that the presence of a seawall is positively correlated with the value of the home protected. However, we find that seawalls are strongly negatively correlated with the value of neighboring properties in Santa Cruz but not in San Diego county, suggesting that the effect of seawalls depend on certain geographical attributes. Our results are robust to accounting for the publicgood nature of locational attributes and the potential spatial dependence of housing prices. Simulation reveals that doubling the extent of seawalls in San Diego and Santa Cruz could reduce property tax revenues by $\$ 7$ million and $\$ 54$ million, respectively.
\end{abstract}

Keywords Seawalls $\cdot$ Hedonic valuation $\cdot$ Coastal erosion $\cdot$ Property values

JEL Classification $\mathrm{H} 23 \cdot \mathrm{Q} 26 \cdot \mathrm{Q} 51 \cdot \mathrm{Q} 54$

Arlan Brucal: Brucal acknowledges support from the Grantham Foundation and the Economic and Social Research Council (ESRC) through the Centre for Climate Change Economics and Policy. John Lynham: Lynham acknowledges support from the Center for Ocean Solutions and valuable research assistance from Qingran Li.

Electronic supplementary material The online version of this article (https://doi.org/10.1007/s1001 8-020-00278-3) contains supplementary material, which is available to authorized users.

Arlan Brucal

a.z.brucal@1se.ac.uk

John Lynham

lynham@hawaii.edu

1 Grantham Research Institute on Climate Change and the Environment, London School of Economics and Political Science, Houghton Street, London WC2A 2AE, UK

2 Department of Economics, University of Hawaii at Manoa, 2424 Maile Way, Saunders Hall 542, Honolulu, HI 96822, USA 


\section{Introduction}

Rising sea levels necessitate careful consideration of the pros and cons of different forms of coastal protection. As sea levels rise, pressure to armor the coast, in the form of seawalls and other protective structures, will likely grow (Caldwell and Segall 2007). ${ }^{1}$ However, putting up a seawall in front of one's property is a classic example of an action with a negative externality. ${ }^{2}$ Seawalls protect individual properties but may impose negative externalities or costs on beachgoers and neighboring properties via accelerated beach loss. If such costs are greater than the private benefits, then seawalls might actually reduce social welfare.

How do seawalls cause accelerated beach loss? First and most obviously, seawalls cause placement loss or the unavailability of the physical area beneath the actual seawall. Second, seawalls restrict the sediment and sand eroding down bluffs that would otherwise replenish and grow beaches. This is known as impoundment loss. Third, they magnify the power of retreating waves, carrying sand out to sea. These outgoing reflected waves strike the sea floor on each outgoing surge, creating a steeper undersea slope. ${ }^{3}$ These steeper slopes then preclude the ability of incoming waves to bring new sand to replenish an already eroded beach. Water in front of the seawalls becomes deep and the shoreline moves landwards, resulting in moderate loss in beach width. This process, called passive erosion, has been observed and studied in different areas (Griggs 2005). Finally, seawalls often cause loss of nearby beaches. The new steep undersea slope prevents sand supply moving down the coast. As a result, neighboring beaches are starved of sand that would otherwise be supplied by shoreline currents (see Griggs and Tait, 1988, and Hall et al., 1990, for detailed case studies, and Griggs, 2009, for an accessible overview).

It is well documented that people enjoy going to the beach (Bin et al. 2005) and that wide sandy beaches are highly valued (Pompe and Rinehart 1995; Pompe 1999; Landry et al. 2003; Landry and Hindsley 2011; Pendleton et al. 2012). Not surprisingly, some studies have found that panoramic view of the beach, greater beachwidth, and shorter distance to the beach have a positive relationship with property valuation (Brown and Pollakowski 1977; Edwards and Gable 1991; Parsons and Wu 1991; Parsons and Powell 2001; Bin et al. 2008a). Some studies employ hedonic valuation methods and find that beach width is positively associated with property value (Pompe and Rinehart 1995; Landry and Hindsley 2011). Others estimate the reduction in property values due to higher erosion risk (Kriesel et al. 1993; Pompe and Rinehart 1995; Bin et al. 2008b; Pompe 2008). Because beach proximity and erosion risk are so highly correlated, separate identification within a hedonic framework is potentially challenging. In a major

\footnotetext{
1 A number of studies reveal that rising sea levels may further expose more properties, facilities, and people to erosion and other physical hazards, thus putting a pressure on their ability to cope with related disasters and to respond to them (Wu et al. 2002).

${ }^{2}$ We define a seawall as a vertical or near-vertical shore-parallel structure designed to prevent erosion and storm surge flooding.

${ }^{3}$ Figure A.1 in the appendix illustrates how coastal armoring accelerates beachloss.
} 
contribution to the literature, Bin et al. (2008a) construct a three-dimensional measure of ocean view that varies independent of erosion risk to separately identify these effects. They find that a greater ocean view significantly increases property value and flood risk significantly lowers property value. In a similar contribution, Gopalakrishnan et al. (2011) correct for potential endogeneity in hedonic models using distance to the continental shelf as instrumental variables to estimate the effect of beachwidth on property values. They find that beach width contributes significantly more to property values than previously believed, with the coefficient of beach width being nearly five times as large as the OLS estimate.

Despite this vast literature documenting the hedonic value of beach width and reduced erosion risk, it remains unclear whether seawalls themselves have a net negative or positive impact on social welfare. There are currently only two hedonic studies on the negative external cost of seawalls and/or other forms of coastal armoring. In the first, Kriesel and Friedman $(2002,2003)$ find that coastal armoring appears to lower property values a few rows inland. They find a negative and statistically significant correlation between property prices in the Southeast US and the degree of coastal armoring on nearby beaches. However, waterfront homes protected by a seawall tend to have higher values than waterfront properties that are unprotected. In the second study, Landry et al. (2003) conduct both a hedonic and a contingent valuation study of coastal armoring. They find a negative but statistically insignificant correlation between property prices on Tybee Island, Georgia, and a visible erosion structure at the nearest shore. Their contingent valuation study confirms that recreational beach visitors have a higher willingness to pay to visit beaches with minimal shoreline armoring (approximately $25 \%$ higher). Thus, the literature to date strongly suggests that people who value beaches do not like beaches with seawalls but there is not an overwhelming amount of evidence that seawalls are correlated with lower property values.

Our goal in this paper is to test whether the presence of a seawall is correlated with higher or lower property values in coastal areas, holding all other determinants of value constant. Our paper is complementary to Kriesel and Friedman $(2002,2003)$ in that we use a very similar approach and data source, however, we use a different subset of the data from a different geographical location: California. In particular, we take data from San Diego and Santa Cruz counties, which offers variation in terms of the extent of spatial dependence in housing prices and differences in the valuation of beach and coastal armoring arising from differences in certain geographical attributes, such as altitude and distance to the water.

In addition, we make a minor methodological improvement over the work of Kriesel and Friedman $(2002,2003)$ by estimating our model while testing and accounting for potential spatial dependence in the estimation procedure and the public good nature of locational attributes. Our work thus serves as both a replication test and an extension of their earlier findings. The rest of the paper is organized as follows. Section 2 presents the conceptual framework and the details of our empirical analysis. Sect. 3 presents the results and Sect. 4 discusses the implications of our findings. 


\section{Conceptual framework}

\subsection{Hedonic valuation of seawalls}

There are various factors that determine house values in coastal areas:

$$
P_{i}=f\left(S_{i}, L_{i}, C_{i}, A_{i}\right),
$$

where $P$ is the price of a house $i, S$ are structural attributes (such as bedrooms, square footage, lot size, etc), $L$ are locational attributes (e.g. distance to the water), $C$ is the degree of coastal armoring on the nearest beach to the property (i.e. $\%$ of waterfront homes with seawalls) and $A$ is an indicator variable that is equal to 1 if the property is waterfront and protected by a seawall.

Suppose the value for property $i$ is expressed as a linear function of each property attribute such that:

$$
P_{i}=\sum_{j=1}^{N_{s}} \lambda_{j} S_{j i}+\sum_{l=1}^{N_{L}} \gamma_{l} L_{l i}+\beta_{1} C_{i}+\beta_{2} A_{i},
$$

where $\lambda$ and $\gamma$ are coefficients on the structural and locational attributes respectively, $\beta_{1}$ and $\beta_{2}$ are our coefficient of interest. If two houses, $r$ and $s$ are identical in $S$ and $L$ then:

$$
P_{r}-P_{s}=\beta_{i}\left(C_{r}-C_{s}\right)+\beta_{2}\left(A_{r}-A_{s}\right),
$$

is an empirically valid measure of the value of coastal armoring on residential properties. This value could be negative or positive, depending on the relative size of the private value to waterfront property owners who built seawalls and the impact of seawall protection of other houses in their locality.

\subsection{Data}

The data employed to perform our analyses are from field measurement and mail survey information collected by the H. John Heinz III Center for Science, Economics and the Environment in 1999. ${ }^{4}$ The Heinz Center published a report in 2000 entitled "Evaluation of Erosion Hazards" (Center 2000). This report was mandated under the National Flood Insurance Reform Act of 1994, and involved a large team of collaborators whose goal was to assess coastal erosion and the resulting loss of property along the ocean and Great Lakes shorelines of the United States. There were many different components to this project but one element involved collecting data on the presence of seawalls and on property prices in coastal communities.

The data on seawalls and erosion risk was collected as follows. Field survey teams were deployed by the Heinz Center to measure and photograph 11,450 different

\footnotetext{
4 The dataset is a result of a study commissioned by the Federal Emergency Management Agency (FEMA). No follow-up study assessments or household surveys were conducted after this study.
} 
structures in 18 coastal counties. The total number of 'surveyed' structures in San Diego was 997 and 746 in Santa Cruz. The entire data set covers approximately 3\% of the structures located within 1,000 feet of the shoreline along the Atlantic coast, Gulf of Mexico, Pacific coast, and the Great Lakes. The dataset was supplemented by other data from county assessor offices, particularly information on the surveyed structures. This was then supplemented with information from detailed questionnaires mailed to the owners of properties within $500 \mathrm{ft}$ of the shoreline within the 18 coastal counties. The Heinz Center research team combined all of this information to calculate the presence and extent of seawalls and beach nourishment projects within the 18 counties. The Heinz Center research team also collected data in the field on the reference elevation of each structure, beach width, and on the distance to an Erosion Reference Feature, typically the top edge of a bluff, dune, vegetation line or beach. This was done by a three-person team using GPS receivers. A complete list of variables and their description is provided in A.6.

The data on property prices and property characteristics was collected from the detailed questionnaire mentioned above. ${ }^{5}$ This mail survey of coastal homeowners was conducted by the Heinz Center, in collaboration with the University of Georgia. In addition to questions regarding the presence of seawalls on local beaches, property owners were asked to report the purchase price of their home, the date purchased, and basic information about the property (number of bedrooms, square footage, etc.). This data was cross-referenced with data on property characteristics collected from county assessor and courthouse records.

The Heinz Center study is one of only a few detailed surveys of seawall locations in the US and is a unique resource for evaluating their impacts. Of the 18 counties studied in the original report, two are in California: San Diego and Santa Cruz counties. In this paper, we focus on the two California counties because previous research using the same dataset centered on the East coast of the US and a California-specific analysis may be useful for informing policy discussions in the state regarding responses to sea level rise and other coastal hazards.

\subsection{Hedonic pricing model}

In terms of implementation, we apply a log-log hedonic pricing model ${ }^{6}$ :

$$
\ln (\text { Property Price })=p_{i}=\beta_{0}+\sum_{n=1}^{N} \beta_{n} \ln X_{n}+\sum_{k=1}^{K} \beta_{k} D_{k}+\varepsilon,
$$

where $X_{n}$ are all continuous independent variables (including the share of armored properties), $D_{k}$ represent dummy variables (including an indicator variable that turns

\footnotetext{
${ }^{5}$ Ideally, property prices should be based on actual sales price. Without access to actual sales data, homeowner estimates of value can serve as reasonably good approximations (Taylor 2003).

${ }^{6}$ We are particularly concerned with the elasticities or percent changes in prices as a result of coastal armoring. This makes the logarithmic form more appropriate. We are also keen on eliminating the effect of outliers to drive our results, which level regressions are more susceptible to.
} 
to unity when the property is armored) and all other terms are as previously defined. We estimate Eq. (4) for the two counties (separately and combined) using simple ordinary least squares. Later on, we relax the assumptions of this method by (1) weighting locational attributes by lot size as proposed by Parsons (1990) to account for the public-good nature of locational attributes and (2) considering potential spatial dependence in housing prices (Cliff and Ord 1970; Can 1990).

It is expected that the seven structural characteristics variables, except the two temporal indicators, should have a positive influence on house prices. Age of house (Years Since Built) can capture the annual deterioration of the physical property and therefore should have a negative effect on house price. Due to price appreciation over this time period, recently sold houses should have higher prices than houses sold a few years ago, so we expect a negative sign on Years Since Last Transaction.

Other variables describe the environmental quality and risk of the structure. Coastal armoring projects (such as seawalls, rip-rap, groins, and breakwaters) are typically installed with the objective to protect properties from erosion damage. Therefore, the Seawall variable is expected to have a positive coefficient in the regression model. For non-waterfront homes, erosion risk is usually not a consideration of the owners. Instead of benefiting from armoring projects, they are likely to worry more about the degradation of beach amenities from seawalls. For unprotected non-waterfront homes, reduced lateral access to shoreline due to coastal armoring can lower their property values (Griggs 2009). This effect is captured by the variable Percent Seawalls, defined as the percent of waterfront structures within a beach community ${ }^{7}$ that reported the presence of shoreline stabilization structures such as seawalls and rip-rap. This is our primary variable of interest and we expect the associated coefficient to be negative. This variable was calculated by dividing the sum of Seawall by the sum of Waterfront within each of the fifteen beach communities in our sample. ${ }^{8}$

Another shoreline protection option, beach nourishment, could also reduce erosion risk to coastal properties while maintaining some beach amenities. The two variables Waterfront Nourishment and Beach Nourishment are expected to have positive correlations with property prices. Respondents reporting beach nourishment only account for a small percentage of the California sample (9\%). Thus, we observe no variation in this variable for the vast majority of houses in our sample. We therefore report results including and excluding those respondents who answered questions relating to beach nourishment.

Elevation refers to the height that the first floor of a home is elevated above the base flood elevation level. The higher the elevation of the house, the better the physical flood protection. Geotime is a measure of erosion risk defined as the number of years until the distance between the property and the erosion reference feature

\footnotetext{
7 Our dataset contains nine San Diego beach communities and six Santa Cruz beach communities, with the largest community having 50 property records. A beach community is defined as all of the buildings located within 1,000 feet of the shoreline.

8 Ideally, the measure of the extent of seawalled coastline should be the total length of seawalls divided by the total length of the coastline in a particular beach community. However, our dataset does not contain the length of seawalls making this metric infeasible to calculate.
} 
Table 1 Summary statistics

\begin{tabular}{|c|c|c|c|c|c|c|c|c|}
\hline & \multicolumn{4}{|c|}{ San Diego } & \multicolumn{4}{|c|}{ Santa Cruz } \\
\hline & Mean & SD & Min & Max & Mean & SD & Min & $\operatorname{Max}$ \\
\hline $\begin{array}{l}\text { Price ('000, in } 2014 \\
\text { US\$) }\end{array}$ & 588.56 & 412.20 & 66.15 & 3120.00 & 699.08 & 600.85 & 71.25 & 3120.00 \\
\hline Seawall (0-1) & 0.18 & 0.38 & 0.00 & 1.00 & 0.19 & 0.39 & 0.00 & 1.00 \\
\hline Percent seawalled (\%) & 39.59 & 17.79 & 0.00 & 61.54 & 42.49 & 21.00 & 0.00 & 100.00 \\
\hline House size (sq. ft.) & 1784.05 & 811.17 & 700.00 & 5000.00 & 2571.56 & 2377.86 & 450.00 & 22000.00 \\
\hline Lot size (sq. ft.) & 5843.64 & 5019.31 & 863.00 & 28239.00 & 8032.56 & 4873.24 & 399.00 & 28106.00 \\
\hline $\begin{array}{l}\text { Years since last trans- } \\
\text { action }\end{array}$ & 14.42 & 10.52 & 1.00 & 42.00 & 18.62 & 12.84 & 0.00 & 55.00 \\
\hline Years since built & 40.09 & 19.86 & 2.00 & 109.00 & 44.78 & 20.56 & 1.00 & 104.00 \\
\hline Fireplace $(0-1)$ & 0.81 & 0.39 & 0.00 & 1.00 & 0.72 & 0.45 & 0.00 & 1.00 \\
\hline Waterfront $(0-1)$ & 0.47 & 0.50 & 0.00 & 1.00 & 0.44 & 0.50 & 0.00 & 1.00 \\
\hline $\begin{array}{l}\text { Waterfront nourish- } \\
\text { ment }(1-0)\end{array}$ & 0.06 & 0.24 & 0.00 & 1.00 & 0.02 & 0.12 & 0.00 & 1.00 \\
\hline $\begin{array}{l}\text { Beach nourishment } \\
\quad(1-0)\end{array}$ & 0.13 & 0.34 & 0.00 & 1.00 & 0.05 & 0.21 & 0.00 & 1.00 \\
\hline Bedroom & 2.93 & 1.09 & 1.00 & 6.00 & 3.19 & 1.47 & 1.00 & 12.00 \\
\hline Geotime & 2289.42 & 6609.13 & 0.47 & 45772.00 & 4895.74 & 8636.80 & 55.96 & 46059.00 \\
\hline Elevation (ft.) & 7801.26 & 4220.72 & -12.30 & 10158.70 & 1327.22 & 3360.50 & -18.00 & 10086.40 \\
\hline Distance to water (ft.) & 186.75 & 162.45 & 1.00 & 803.35 & 249.77 & 161.57 & 29.05 & 670.38 \\
\hline Beach width & 81.21 & 286.96 & 0.00 & 3000.00 & 38.39 & 179.09 & 0.00 & 2000.00 \\
\hline Built Post-FIRM & 0.05 & 0.21 & 0.00 & 1.00 & 0.07 & 0.25 & 0.00 & 1.00 \\
\hline Year of purchase & 1985 & 10.52 & 1957 & 1998 & 1980 & 12.84 & 1944 & 1999 \\
\hline Observations & 132 & & & & 151 & & & \\
\hline
\end{tabular}

Source of basic data: The Heinz III Center for Science, Economics, and Management (Center 2000)

(ERF) is reduced to zero. To compute this variable, the erosion rate at each property location is calculated first. Since in some areas erosion rates can be determined from historical records, while in others they are affected by protection devices such as seawalls, we applied the same method used in the Heinz Center's erosion hazard report. A detailed description of this formulation is presented in Appendix B. A squared logarithm of Geotime is added to the model to test for a non-linear effect. Built Post-FIRM is an indicator variable for whether or not the home was built post the publication of a Flood Insurance Rate Map (FIRM) for the surrounding area. Post-FIRM homes typically have lower insurance premiums if they are built above base flood elevation levels, therefore we expect the coefficient on this variable to be positive.

Table 1 presents summary statistics for all of our main variables. On the average, properties in Santa Cruz are generally more expensive compared to those in San Diego. This is probably due to bigger houses and lot sizes. Houses in San Diego are also situated in higher places and closer to the water, which implies that these houses are potentially in high cliffs above water (Griggs and Savoy 1985). The difference in 
this locational attribute should provide more insights on the effect of seawalls on inland property. In particular, seawalls in Santa Cruz should affect inland properties much more than they could in San Diego. The extent of seawalled properties are about the same for the two counties, which makes these two cases comparable.

\section{Results}

\subsection{OLS results}

We start our analysis with an ordinary least squares (OLS) method using all the variables listed in Table A.6. We did separate analysis for San Diego and Santa Cruz to account for the potential difference in hedonic price functions between these two market segments. We also run combined observations from the two counties to formally test this difference by adding a San Diego indicator variable that turns on when the property is situated in San Diego County. Results are summarized in Table 2.

For San Diego, we reject the null hypothesis of no correlation for only 4 variables. In particular, we find that price increases by about $0.50 \%$ as the size of a house increases by one percent. ${ }^{9}$ This translates to a marginal implicit price of house size by about $\$ 164 /$ sq.ft. ${ }^{10}$ Lot size has smaller marginal implicit price, with houses being valued more by about $\$ 37$ as lot size increases by sq.ft. Waterfront is surprisingly not significant. This is possibly due to fact that most houses in San Diego are situated in high cliffs above water and beach is not easily accessible. Surprisingly, homeowners value having a fireplace in their homes, considering that most areas of San Diego rarely require a fireplace for heating. This is possibly because we did not explicitly know whether it is outdoor or indoor fireplaces. Outdoor fireplaces may be associated with homeowners' valuation of outdoor living, which makes this structural attribute a worthy investment. ${ }^{11}$

In Santa Cruz, house size is positively correlated with housing prices. However, since houses in Santa Cruz are larger on the average, the implicit marginal price of house size is smaller at $\$ 135 / \mathrm{sq}$.ft. The same observation holds true for lot size, with Santa Cruz houses being valued by $\$ 32$ more per additional sq.ft. Waterfront, in contrast to San Diego, is significantly associated with higher housing prices in Santa Cruz. In particular, waterfront houses in Santa Cruz are valued more by about $40 \%$,

\footnotetext{
9 We recognize that all of our regression coefficients should be interpreted as elasticities, although we remain silent on the direction of causality. See Gopalakrishnan et al. (2011) for a discussion of the endogeneity problem in hedonic beach value models and for a potential solution.

10 We calculate marginal implicit price (\$ per unit) for the logged variables as:

$$
\text { Marginal Implicit Price }=\frac{\beta_{k}}{\bar{x}_{k}} \times \bar{p}
$$

where $\beta_{k}$ is the estimated coefficient of the regressor $x_{k}$, and $\bar{x}_{k}$ and $\bar{p}$ are the unconditional means of the regressor $x_{k}$ and the dependent variable $p$, respectively.

11 The National Association of Realtors 2013 Home Features Survey reveals that $57 \%$ chose homes with at least one fireplace.
} 


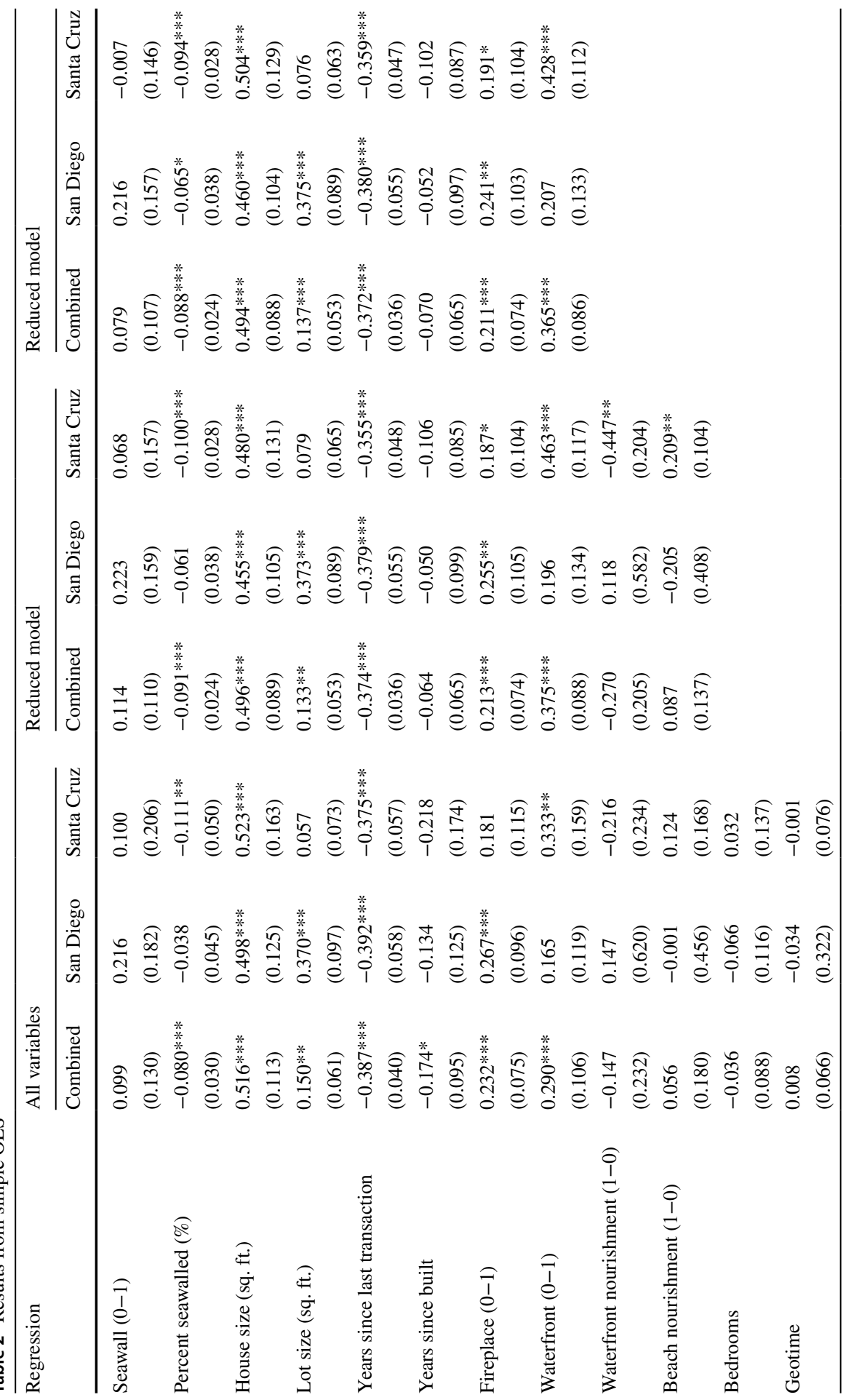




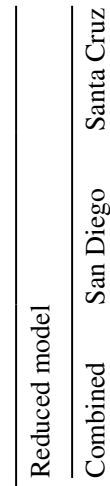

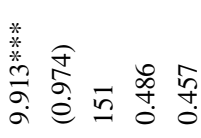

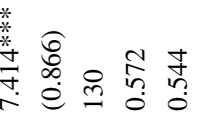

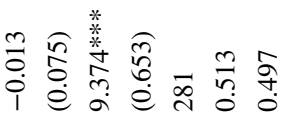

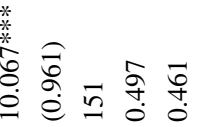

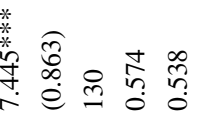

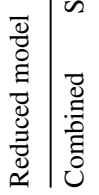

$\frac{\overrightarrow{0}}{\frac{0}{0}}$

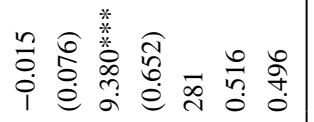

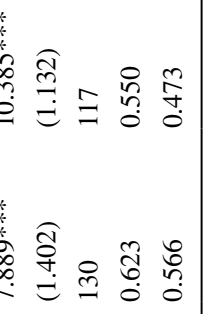

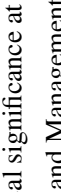

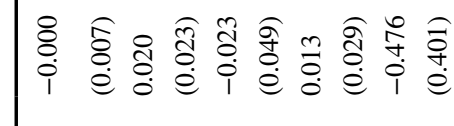

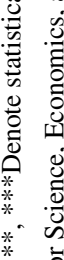

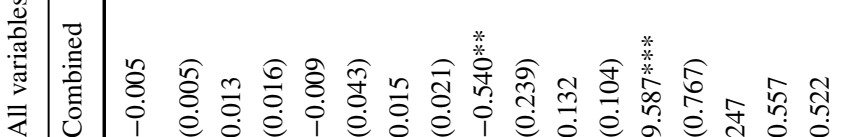

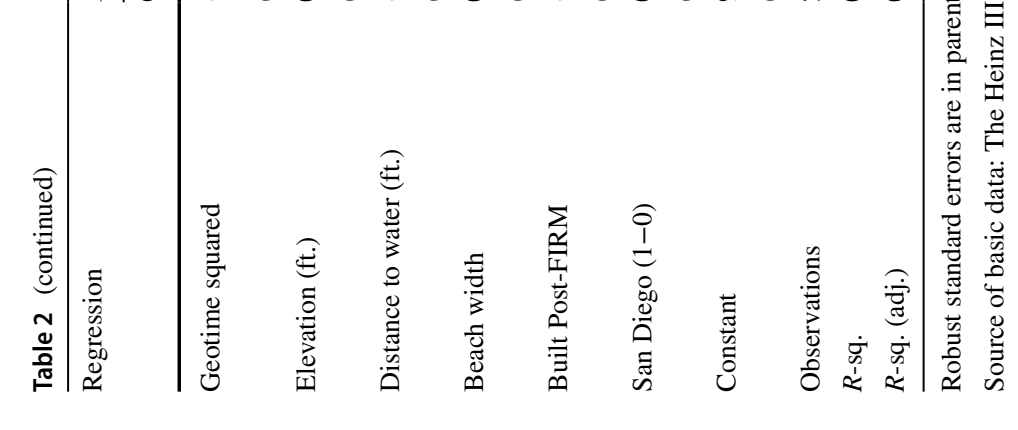

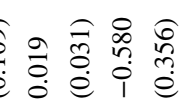

*

志

章 
posting a marginal implicit price of more than $\$ 232,000 .{ }^{12}$ The existence of fireplace, while positive, is not significantly correlated with housing prices.

Overall, we find no strong evidence to suggest that there are systematic differences in housing prices between the two counties or market segmentation (Taylor 2003). Our OLS regression finds that the San Diego dummy, while positive, is statistically insignificant. We also performed Wald test for San Diego dummy and found the $F$-statistic insignificant, with the value of 1.60 and $p$ value equivalent to 0.207.

The variables indicating flooding and erosion risks (e.g.Geotime, Elevation) do not appear to be significantly correlated with property prices. This is true when we analyze housing prices in each county separately and after combining observations from the two counties. This is different from the findings in Kriesel and Friedman (2003). This could potentially be explained by the different nature of the shorelines between the two regions. Unlike the Atlantic and Gulf coast, much of the Pacific coastline consists of narrow beaches backed by steep cliffs. Cliff erosion is site specific and episodic, which is often hidden by the low long-term average erosion rate. Only 45 observations in our entire sample have a Geotime less than 100 years. It is likely that erosion risk is not reflected in property prices till decades later.

Although the low long-term erosion rate might reduce homeowners' perceptions of the erosion threat to their properties, shoreline management policies can still affect house buyers' awareness of erosion risk levels. Regarding the seawall indicators, we obtain remarkably similar results to Kriesel and Friedman (2003) and Kriesel et al. (2005). The coefficient on Seawall is positive but not statistically significant in either county. The imprecision of this estimate relative to Kriesel and Friedman (2003) could be due to our smaller sample size. We evaluate the effect of seawalls on housing prices using combined samples to increase the sample size and observe same result.

Meanwhile, we notice a significant negative effect of Percent Seawalls on property prices in Santa Cruz. This suggests that property owners in the county are worse off as a result of extensive coastal armoring. Furthermore, our coefficient of -0.11 is more than three times larger than the -0.03 found by Kriesel and Friedman (2002). This suggests that, as the percentage of waterfront coastal armoring in a community increases by $100 \%$, the associated value of a house located on the Santa Cruz coast drops by $\$ 77,597$. In contrast, we do not find any strong evidence to suggest that the extent of armored coastline in San Diego has an effect on property values. If there is an effect, house values in San Diego declines by about $\$ 22,365$ if the share of waterfront coastal armoring in a community increases by $100 \%$. Interestingly, our estimate falls within the ballpark of Kriesel and Friedman (2003) who found that for the same percentage increase in coastal armoring, house prices on the Atlantic and Gulf coasts drop by $\$ 41,091$ in 2014 dollars.

\footnotetext{
12 For dummy variables, the calculated marginal implicit price is expressed as:$$
\text { Marginal Implicit Price }=\left(e^{\beta_{k}}-1\right) \times \bar{p}
$$

where $\beta_{k}$ and $p$ are as previously defined.
} 


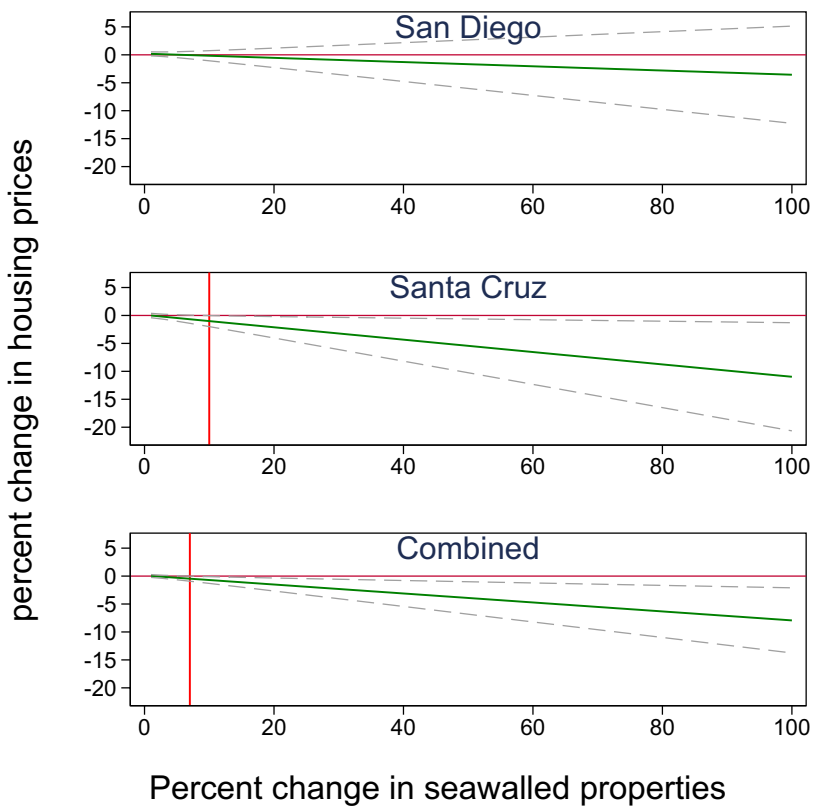

Fig. 1 Estimated percent change in housing prices relating to percent change in seawalled properties in San Diego and Santa Cruz counties. Source: Authors' estimates

To analyze the net effect of building a seawall from a point of view of a marginal house, we need to account for the joint effect of building a seawall in front of the property and the added armored coastline on housing prices. Figure 1 summarizes the results using estimates from Table $2 .{ }^{13}$ The solid green line reflects the change in the property value of the marginal household from building a seawall, given an assumed change in the share of armored waterfront properties in the county. In San Diego, even if a group of coastal households decides to build seawalls on their properties, bringing the share of armored properties to $80 \%$, we will not find any statistically significant effect on their housing prices. In contrast, we find a significant drop in the value of a marginal house in Santa Cruz if building a seawall would result in an increase in armored waterfront properties by just about $9 \%$ (see vertical red line). The drop in the property resale values is about $1 \%$ and can go up to $10 \%$ if building seawalls would result in increasing the current share of protected waterfront properties from 42 to $84 \%$.

We also ran two OLS models with a smaller subset of variables in order to omit variables that seemed unimportant and slightly increase our sample size for Santa Cruz. The results of these reduced models are presented in columns 5 through 10

\footnotetext{
13 Calculation of the net effect of coastal armoring is given by:

Net Effect $=\beta_{\text {seawall }} \times$ Seawall $(0-1)+\beta_{\text {percent seawalled }} \times$ Percent Seawalled

Confidence intervals are calculated using delta method.
} 
in Table 2. The coefficients that are statistically significant in the reduced models are mostly consistent with those in the complete model. The coefficient on Seawall is still not statistically significant. The coefficient on Percent Seawalls is about the same level as shown in Table 2 for Santa Cruz but larger for San Diego and marginally significant when we remove variables relating to nearby and front beach nourishment.

We also consider the world as suggested by Parsons (1990) in which locational amenities are pure public goods and as a result the hedonic function must have such attributes weighted by lot size. He pointed that weighting would account for the opportunity cost imposed by landowners with larger properties on others within their neighborhood, thus avoiding bias in the marginal price of locational attributes. This setting is quite applicable to our analysis because the number of individuals that may enjoy the benefits of a beach of certain quality is limited by the area of land over which that amenity is available. For example, there is a fixed amount of land within a mile from the Natural Bridges State Beach in Santa Cruz. Thus, the more land is taken by one household in a nearby location, the less available to others the benefits associated with living nearby the beach. Parsons (1990) argues that the size of this opportunity cost imposed on others is proportional to the size of the lot occupied by the landlord.

To account for the pure public good nature of location attributes, we modified Eq. (2) using the log-transformed price per unit of land as the dependent variable. This procedure is equivalent to a weighting rule suggested by Parsons (1990), which allows locational attribute prices to vary proportionally with the amount of land occupied. Results using this method are shown in rows $2-4$ of Table A.7. The coefficients of our variables of interest, namely Seawall and Percent Seawall, are comparable to the baseline result. We also formulate hedonic price regressions without the structural attributes similar to Diamond (1980) (see rows 5-7 of Table A.7). Our results remain robust and similar to the baseline results.

We first test the robustness of our estimates by running a median regression. ${ }^{14}$ Contrary to simple OLS, median regression does not rely on strict assumptions in relation to the distribution of the residuals. This is particularly useful when our dependent variable (i.e. housing prices) is bimodal or multimodal and when the source multimodality is known. ${ }^{15}$ Results, as presented in A.11, show fairly similar to the baseline results.

Finally, we performed other regressions, such as specifying with years-since-lasttransaction dummies (instead of log-transformed continuous variable) and with the same sample size across different specifications. ${ }^{16}$ Regression results are presented in Tables A.9 and A.10. Our results remain stable and generally similar with the baseline estimates.

\footnotetext{
${ }^{14}$ Due to the relatively small sample size, an anonymous referee suggested to run a median regression.

${ }^{15}$ See Figure A.2 for the distribution of log-transformed housing prices for San Diego and Santa Cruz counties.

${ }^{16} \mathrm{We}$ are indebted to an anonymous referee for recommending these procedures to test the robustness of our baseline estimates.
} 

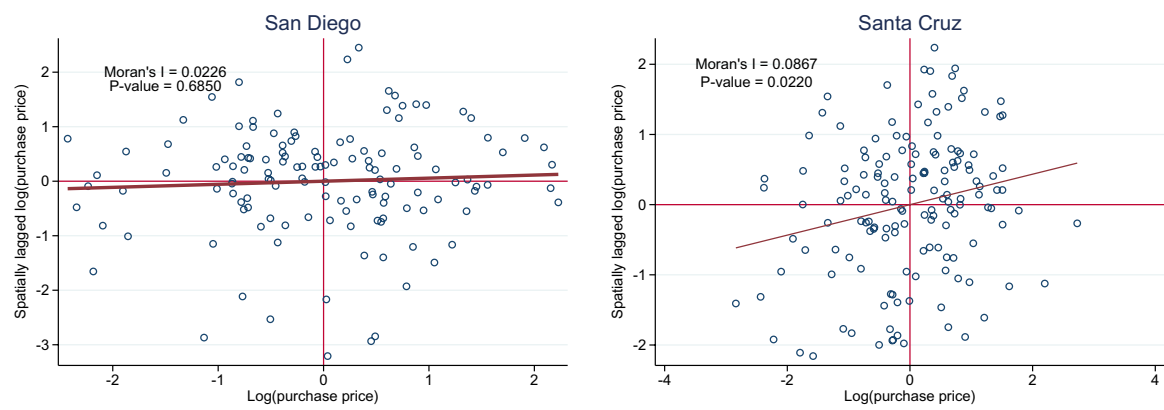

Fig. 2 Moran scatterplots for Housing Prices in San Diego and Santa Cruz counties Source of basic data: The Heinz III Center for Science, Economics, and Management (Center 2000)

\subsection{Accounting for spatial dependence}

Testing for the presence of spatial autocorrelation in studying housing prices is important principally because the presence of spatial dependence violates one of the major properties of regression analysis - the independence across observations (Can 1990). Ignoring spatial autocorrelation can lead to biased parameter estimates and misleading significance levels. In our context, if the prices of nearby houses have an absolute effect on each other, potentially due to the fact that some sellers or buyers assess a given property not only based on location but also on prices of nearby houses, then we may need to add spatial autoregressive terms in our specification. Equation (2) becomes a model with $N$ cross-section units for each $i \in N$ as specified below:

$$
P_{i}=\lambda \mathbf{W P}+\mathbf{X}_{i} \boldsymbol{\beta}+\varepsilon_{i}
$$

with

$$
\varepsilon=\rho \mathbf{W} \varepsilon+u
$$

where $\mathbf{W}$ is an $n \times n$ inverse distance weight matrix, WP is a vector of the spatially lagged house prices and $\lambda$ and $\rho$ are the unknown spatial lagged parameters. $\mathbf{X}$ is a vector of explanatory variables, including Seawall and Percent Seawall, and $u$ is a standard i.i.d. error term.

We account for the presence of spatial autocorrelation as specified in alternative forms. In particular, we test for the following hypotheses: (1) $\lambda=0, \rho \neq 0$ which leads to a spatial lag model (SLM); $\lambda \neq 0, \rho=0$ leading to spatial errors model (SEM); and (3) $\lambda \neq 0, \rho \neq 0$ leading to a spatial $\operatorname{ARAR}(1,1)$ model (Arraiz et al. 2010).

\subsubsection{Tests for spatial dependence}

A convenient and perhaps the most transparent way of testing for spatial dependence is in terms of graphical representation. Figure 2 shows the Moran scatterplot of house prices for San Diego and Santa Cruz counties. Moran scatterplots show the relationship between the individual house's price (in standardized form) in the 
Table 3 Tests for global spatial autocorrelation

\begin{tabular}{llll}
\hline & San Diego & Santa Cruz & Combined \\
\hline $\begin{array}{l}\text { Distance of nearest } \\
\text { neighbor (in kms) }\end{array}$ & & & \\
Mean & 1.279 & 0.042 & \\
Min & 0.931 & 0.006 & \\
Max & 3.336 & 0.239 & \\
Moran's I & 0.023 & $0.087^{* *}$ & $0.054^{*}$ \\
& $(0.049)$ & $(0.037)$ & $(0.022)$ \\
Geary $c$ & 0.943 & $0.900^{* *}$ & $0.924^{* *}$ \\
& $(0.051)$ & $(0.040)$ & $(0.024)$ \\
\hline
\end{tabular}

The estimated standard deviation of each statistic are in parentheses. $*, * *, * *$ Represents significance at 10,5 and $1 \%$, respectively

horizontal axis and the average prices of neighboring houses weighted by the spatial lag vector $\mathbf{W}$ in the vertical axis. We assume that the degree of spatial dependence of a particular house is inversely related to the geographic distance between the two properties. That is,

$$
\begin{aligned}
\mathbf{W} & =\left(\begin{array}{ccccc}
0 & w_{1,2} & w_{1,3} & \ldots & w_{1, n} \\
w_{2,1} & 0 & w_{2,3} & \ldots & w_{2, n} \\
w_{3,1} & w_{3,2} & 0 & \ldots & w_{3, n} \\
\vdots & \vdots & \vdots & \ddots & \vdots \\
w_{n, 1} & w_{n, 2} & w_{n, 3} & \ldots & 0
\end{array}\right) \\
w_{i, j} & =\frac{1}{d_{i j}} .
\end{aligned}
$$

We find evidence of positive spatial dependence for houses located in Santa Cruz. The Moran statistic is 0.0867 and is statistically significant at 5\% level. In contrast, there is no strong evidence to suggest that housing prices in San Diego are spatially dependent.

We formally test for the presence of global spatial autocorrelation by calculating Moran's I (Moran 1950) and Geary c (Cliff and Ord 1970). We then determine the significance of these statistics following the procedure suggested by Pisati (2001). Table 3 summarizes the results. The tests confirm our graphical approach suggesting no strong spatial dependence of house prices in San Diego. In contrast, there is strong evidence of spatial autocorrelation of house prices in Santa Cruz. The spatial autocorrelation persists even if we combined the two datasets.

\subsubsection{Hedonic prices with spatial dependence}

With an indication of potential spatial dependence, we re-estimate Eq. (2) using data on Santa Cruz county house prices. This time, we relax the assumption that $\lambda$ and $\rho$ are both zero. We estimate parameters based on models with spatial dependence in a maximum likelihood framework using the procedure suggested by Drukker et al. 
(2015). We employ different specifications to potentially account for different forms of spatial autocorrelation, namely spatial lag model, spatial error model and the spatial ARAR(1,1,) model. ${ }^{17}$ Then, for each model, we run three different specifications similar to the simple OLS regression in which we start with all the variables and drop some of them to slightly increase our sample. We do this to test the stability of our estimates. Results are presented in Table 4.

We start the analysis by looking at the estimated spatial autocorrelation parameters. We find no strong evidence to suggest that there exists spatial autocorrelation. In particular, we fail to reject the null hypotheses that (1) $\lambda=0, \rho \neq 0$; (2) $\lambda \neq 0, \rho=0$; and (3) $\lambda \neq 0, \rho \neq 0$ in Eq. (6). ${ }^{18}$

The estimated effect of changes in the variables of interest, even after accounting for potential spatial dependence, remains robust and consistent with our baseline results. The coefficient remains insignificant for the indicator variable Seawall. Nonetheless, the coefficient for the extent of coastline armoring (Percent Seawalls), remains negative albeit slightly smaller and statistically significant. This confirms our earlier result that as the percentage of waterfront coastal armoring in a beach community increases, the associated value of houses located in San Diego and Santa Cruz drops significantly. Moreover, our estimates remain stable across different forms of assumed spatial dependence and under different sets of controls, thus increasing our confidence on the robustness of the results.

\section{Discussion}

We find that the sales price of a house located within 1,000 feet of the coast in San Diego and Santa Cruz counties is correlated with its structural characteristics and the shoreline management policies taken in the community. Although seawalls protect coastal structures from erosion damages, the negative coefficient on Percent Seawalls calls for attention to the welfare impacts of coastal armoring on waterfront and non-waterfront households.

Using our baseline estimates, we predicted the potential change in total housing values for the two counties when the share of those that are protected by seawalls increases by a certain percentage (see Table 5). Results suggest that doubling the current level of properties protected by seawalls may be associated with a $\$ 20,954.16$ drop in the resale value of an average coastal home in San Diego that is protected by seawalls. For those that are not protected by seawalls, the magnitude

\footnotetext{
17 Thanks to an anonymous referee, we recognized that the estimation of a SARAR model may introduce more problems than solving them. Nonetheless, the employment of different specifications, including the SARAR, is meant to show that our estimates, particularly on seawall protection, are consistent and robust over different specifications of spatial dependence. We refrain to interpret the actual estimates due to uncertainties in the type of spatial dependence.

18 We also perform diagnostic tests for spatial dependence in an OLS framework after estimating Eq. (2), following the procedure as suggested by Pisati (2001). Results are summarized in Table A.8. We find no strong evidence to suggest that there is spatial dependence amongst observed housing prices in each county.
} 


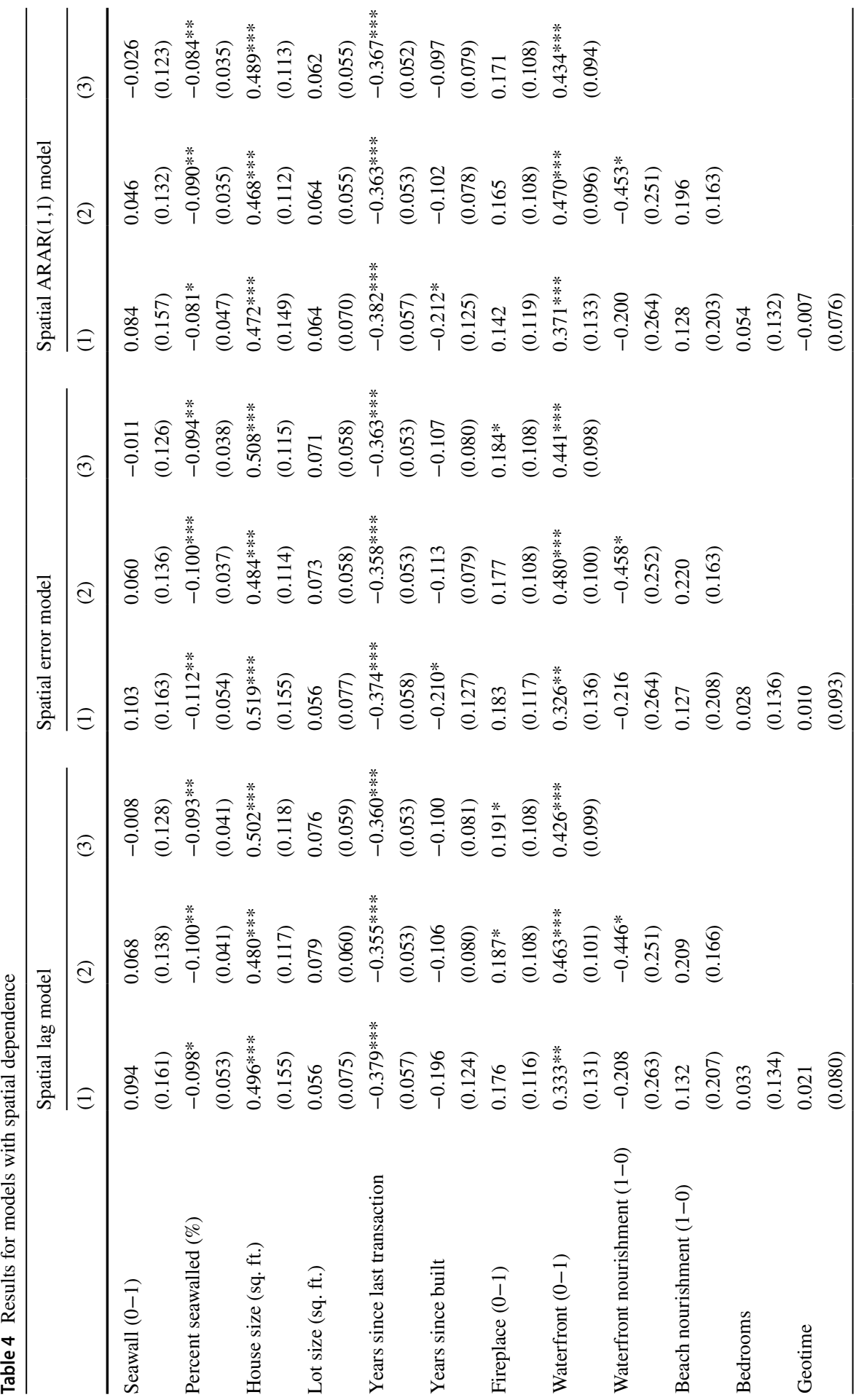




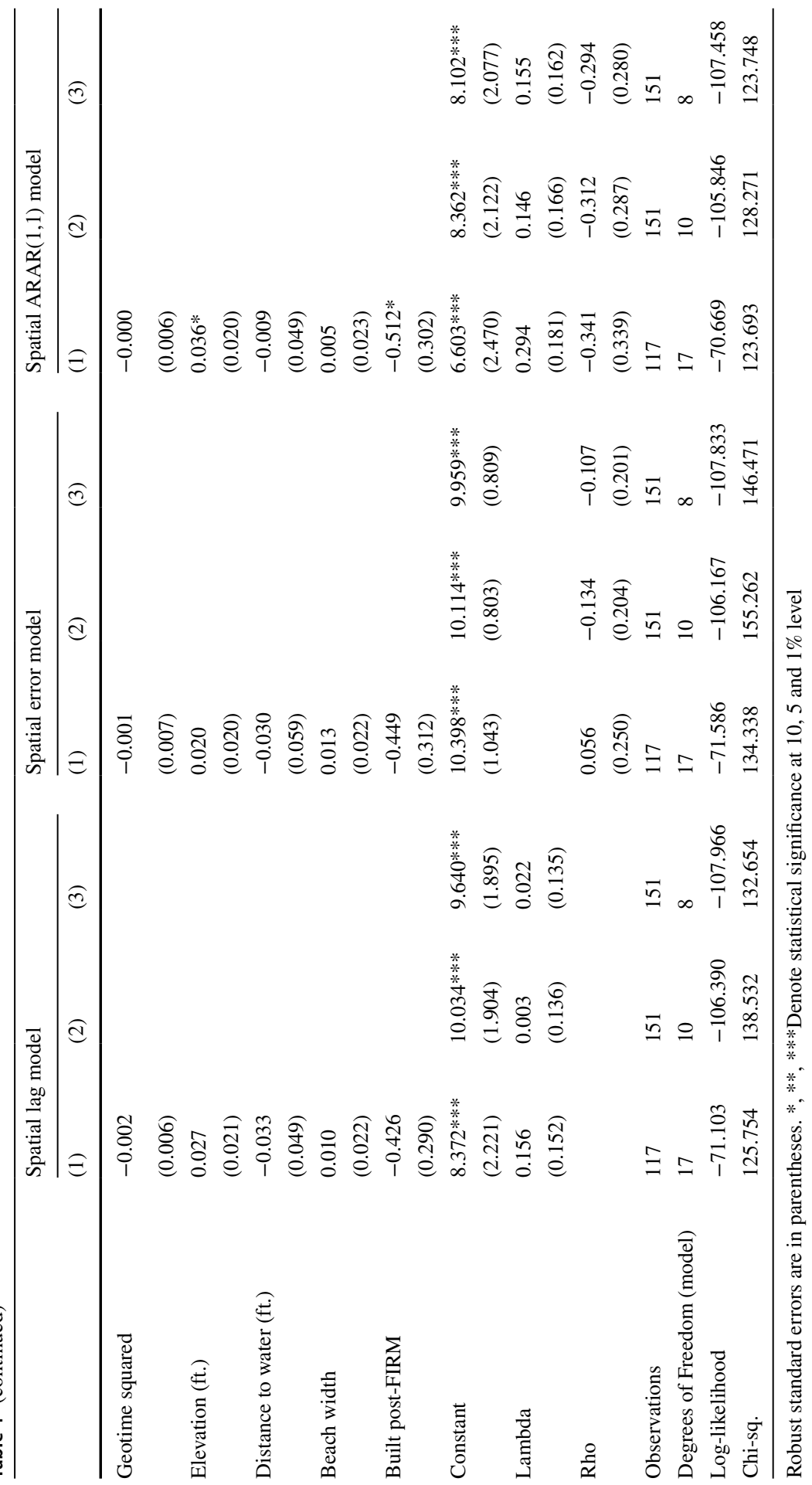


Table 5 Potential effect of increasing the share of waterfront households protected by seawalls

\begin{tabular}{|c|c|c|c|c|c|c|}
\hline \multirow{2}{*}{$\begin{array}{l}\% \text { Change in } \\
\text { seawalls (from } \\
\text { current mean) }\end{array}$} & \multicolumn{2}{|c|}{ Change in price } & \multicolumn{2}{|c|}{ No. of affected houses } & \multirow{2}{*}{$\begin{array}{l}\text { Total effect } \\
\text { (in '000\$) }\end{array}$} & \multirow{2}{*}{$\begin{array}{l}\text { Revenue } \\
\text { loss } \\
\text { (in '000\$) }\end{array}$} \\
\hline & (in \$) & (in \$) & Seawalled & Non-seawalled & & \\
\hline \multicolumn{7}{|l|}{ San Diego } \\
\hline 1.00 & 10.47 & -223.65 & 14,397 & 19,542 & $-4,219.92$ & -42.20 \\
\hline 5.00 & 7.90 & $-1,118.26$ & 14,967 & 18,972 & $-21,097.37$ & -210.97 \\
\hline 10.00 & -95.32 & $-2,236.53$ & 15,680 & 18,259 & $-42,331.75$ & -423.32 \\
\hline 20.00 & -635.10 & $-4,473.06$ & 17,105 & 16,834 & $-86,161.88$ & -861.62 \\
\hline 30.00 & $-1,619.35$ & $-6,709.58$ & 18,531 & 15,408 & $-133,391.07$ & $-1,333.91$ \\
\hline 40.00 & $-3,048.07$ & $-8,946.11$ & 19,956 & 13,983 & $-185,919.98$ & $-1,859.20$ \\
\hline 50.00 & $-4,921.25$ & $-11,182.64$ & 21,382 & 12,557 & $-245,649.31$ & $-2,456.49$ \\
\hline 60.00 & $-7,238.90$ & $-13,419.17$ & 22,807 & 11,132 & $-314,479.74$ & $-3,144.80$ \\
\hline 70.00 & $-10,001.02$ & $-15,655.70$ & 24,232 & 9,707 & $-394,311.94$ & $-3,943.12$ \\
\hline 80.00 & $-13,207.60$ & $-17,892.22$ & 25,658 & 8,281 & $-487,046.53$ & $-4,870.47$ \\
\hline 90.00 & $-16,858.64$ & $-20,128.75$ & 27,083 & 6,856 & $-594,584.26$ & $-5,945.84$ \\
\hline 100.00 & $-20,954.16$ & $-22,365.28$ & 28,509 & 5,430 & $-718,825.86$ & $-7,188.26$ \\
\hline \multicolumn{7}{|l|}{ Santa Cruz } \\
\hline 1.00 & -0.74 & -775.98 & $2,840.12$ & $4,189.88$ & $-32,533.71$ & -325.34 \\
\hline 5.00 & -158.54 & $-3,879.89$ & $2,952.60$ & $4,077.40$ & $-162,879.83$ & $-1,628.80$ \\
\hline 10.00 & -704.13 & $-7,759.79$ & $3,093.20$ & $3,936.80$ & $-327,267.40$ & $-3,272.67$ \\
\hline 20.00 & $-2,956.45$ & $-15,519.58$ & $3,374.40$ & $3,655.60$ & $-667,096.04$ & $-6,670.96$ \\
\hline 30.00 & $-6,756.96$ & $-23,279.37$ & $3,655.60$ & $3,374.40$ & $-1,032,546.40$ & $-10,325.46$ \\
\hline 40.00 & $-12,105.67$ & $-31,039.15$ & $3,936.80$ & $3,093.20$ & $-1,436,679.04$ & $-14,366.79$ \\
\hline 50.00 & $-19,002.57$ & $-38,798.94$ & $4,218.00$ & $2,812.00$ & $-1,892,554.72$ & $-18,925.55$ \\
\hline 60.00 & $-27,447.66$ & $-46,558.73$ & $4,499.20$ & $2,530.80$ & $-2,413,233.60$ & $-24,132.34$ \\
\hline 70.00 & $-37,440.95$ & $-54,318.52$ & $4,780.40$ & $2,249.60$ & $-3,011,776.64$ & $-30,117.77$ \\
\hline 80.00 & $-48,982.43$ & $-62,078.30$ & $5,061.60$ & $1,968.40$ & $-3,701,244.16$ & $-37,012.44$ \\
\hline 90.00 & $-62,072.11$ & $-69,838.09$ & $5,342.80$ & $1,687.20$ & $-4,494,696.64$ & $-44,946.97$ \\
\hline 100.00 & $-76,709.97$ & $-77,597.88$ & $5,624.00$ & $1,406.00$ & $-5,405,194.88$ & $-54,051.95$ \\
\hline
\end{tabular}

I. San Diego County has 70 miles of coastline. Based on a very conservative estimate of housing density (4 homes per acre), this means that there are approximately 33,939 homes within 1,000 feet of the shoreline. $42 \%$ of these homes are currently protected by seawalls. Property tax in San Diego County is a little more than $1 \%$.

II. Santa Cruz County has 29 miles of coastline. Based on an even more conservative estimate of housing density ( 2 homes per acre), this means that there are approximately 7,030 homes within 1,000 feet of the shoreline. $40 \%$ of these homes are currently protected by seawalls. Property tax in Santa Cruz County is a little more than $1 \%$.

III. The change in price for seawalled properties is calculated using the estimated coefficients of the Seawall and Percent Seawall in our baseline model (i.e., OLS including all variables). The unconditional mean property price for each county is used as the base price $(\$ 588,000$ for San Diego and $\$ 699,000$ for Santa Cruz.). For non-seawalled properties, we just used the coefficient for Percent Seawall

is larger at $\$ 22,365$. Overall, the said increase in the share of protected properties translates to more than $\$ 718$ million reduction in the value of affected houses in the county. In terms of property tax revenues, a very crude back-of-the-envelope 
calculation suggests that this increase would cost the government $\$ 7$ million in terms of revenue loss and the discounted present value of this annual loss is $\$ 143$ million. ${ }^{19}$

For Santa Cruz County, the potential effect of increasing the current share of seawalled properties by $100 \%$ is significantly greater, reaching to about a $\$ 77,000$ decline in home resale values for protected properties. For non-seawalled properties, the effect is about similar at $\$ 78,000$. This implies that there is no positive net benefit of putting up an additional seawall from the current level. The increase in the seawalled-properties is associated with the loss in the total value of coastal homes in the county by more than $\$ 5.4$ billion. This translates to a government revenue loss of about $\$ 54$ million, which is equivalent to a discounted present value of about $\$ 1.08$ billion.

Although our estimates are large, the associated welfare impacts are consistent with the existing literature. Our findings are in line with Kriesel and Friedman (2003) and Kriesel et al. (2005) who find negative, albeit smaller, effects on property prices. Landry et al. (2003) also found a negative effect, but their estimated effect was statistically insignificant. However, their contingent valuation study strongly suggests that beachgoers do not like beaches with seawalls. The existing literature suggests that our estimates might even be underestimated. Gopalakrishnan et al. (2011) correct for endogeneity bias and find that the beach width effect on property prices is almost five times larger. Furthermore, they find that the long- term net value of coastal residential property can fall by as much as $52 \%$ when the erosion rate triples. To the extent that seawalls can potentially double or triple erosion rates on neighboring non-protected properties, our estimates are very much in line with their results.

Our paper does not come without limitations. Aside from potential measurement problems associated with the survey-based price variable and the inability to control for unobserved systematic patterns across beach communities, our study may also be confounded by the potential immunity of the property market to climate risks, which may be coupled with households' potential downward bias against these risks. To be more precise, if property buyers underestimate the risk of floods/erosion, then the benefits of seawalls will be vastly undervalued while the negative consequences would remain. Moreover, we find that variables indicating flooding and erosion risks are not significantly correlated with property prices, which could indicate that home buyers are myopic. Another possibility is that home buyers assess the risk accurately but that it is quite low or even non-existent. Both possibilities could be because there were no flood episodes in the study areas in the years prior to the survey. Most of the prior flood episodes were in Northern California. There has been no major impacts in Central California until 2017 when Hurricane Marie caused flooding in the region.

Even in the absence of flooding and erosion, more recent information of progressing climate change, climate change reporting, and extreme events might have

\footnotetext{
${ }^{19}$ Property tax in San Diego County is a little more than $1 \%$. Using the annual discount rate of $5 \%$, an infinite stream of annual losses of $\$ 7.188$ million would be $\$ 7.188 \mathrm{~m} / 0.05=\$ 143.765 \mathrm{~m}$.
} 
changed perspectives about coastal armoring in more recent years. Moreover, potential buyers may also shy away from purchasing properties with visible protection measures, which may compel homeowners to opt not to install coastal defense measures. How these issues influence property housing, along with the determination of the most cost-effective approach to deal with increasing sea level rise, are some of the areas which future research should explore.

There are also issues relating to the estimation of the potential effect of seawall protection on housing values while disentangling the effect of spatial dependence on the variable of interest. ${ }^{20}$ These issues include potential over-connectivity as argued by Smith (2009). Moreover, our house price variable is technically from different time periods, which implies that the weight matrix should limit the spatial relations among the transactions (Dubé et al. 2016). Thus, the spatial relations in our models necessarily assume that dependence is purely cross-sectional. While we recognize these estimation issues, determining their implications on the estimated parameters is beyond the scope of this study.

Despite the above methodological concerns, our paper represents a step forward in terms of measuring a previously unmeasured social cost (in California). Furthermore, the correlation with house prices is only one of the many ways that seawalls might impose social costs and benefits. Recreational and existence values of beaches are also clearly important. Our paper finds that properties near beaches with significant seawall protection are selling for lower prices than those without. This information is easily observed, collected, and defensible. Even though we are still missing many of the social costs associated with seawalls, our hedonic estimates and implied welfare costs are so large that this raises serious questions about whether seawalls in California pass a simple cost-benefit analysis. The benefits to individual waterfront property owners would have to be extremely large to justify the social costs.

Open Access This article is licensed under a Creative Commons Attribution 4.0 International License, which permits use, sharing, adaptation, distribution and reproduction in any medium or format, as long as you give appropriate credit to the original author(s) and the source, provide a link to the Creative Commons licence, and indicate if changes were made. The images or other third party material in this article are included in the article's Creative Commons licence, unless indicated otherwise in a credit line to the material. If material is not included in the article's Creative Commons licence and your intended use is not permitted by statutory regulation or exceeds the permitted use, you will need to obtain permission directly from the copyright holder. To view a copy of this licence, visit http://creativecommons.org/licen ses/by/4.0/.

\section{References}

Arraiz I, Drukker DM, Kelejian HH, Prucha IR (2010) A spatial Cliff-Ord-type model with heteroskedastic innovations: small and large sample results. J Reg Sci 50(2):592-614

Bin O, Landry CE, Ellis CL, Vogelsong H (2005) Some consumer surplus estimates for North Carolina beaches. Mar Resour Econ 20(2):145-161

Bin O, Crawford TW, Kruse JB, Landry CE (2008a) Viewscapes and flood hazard: coastal housing market response to amenities and risk. Land Econ 84(3):434-448

\footnotetext{
${ }^{20}$ We are indebted to an anonymous referee for pointing out the issues in relation to estimating spatial lag models.
} 
Bin O, Kruse JB, Landry CE (2008b) Flood hazards, insurance rates, and amenities: evidence from the coastal housing market. J Risk Insur 75(1):63-82

Brown GM, Pollakowski HO (1977) Economic valuation of shoreline. Rev Econ Stat 59:272-278

Caldwell M, Segall CH (2007) No day at the beach: sea level rise, ecosystem loss, and public access along the California coast. Ecol LQ 34:533

Can A (1990) The measurement of neighborhood dynamics in urban house prices. Econ Geogr 66(3):254-272

Cliff AD, Ord K (1970) Spatial autocorrelation: a review of existing and new measures with applications. Econ Geogr 46(sup1):269-292

Center Heinz (2000) Evaluation of erosion hazards. Economics and the environment. The H. John Heinz III Center for Science, Washington, DC

Diamond DB (1980) The relationship between amenities and urban land prices. Land Econ 56(1):21-32

Drukker DM, Peng H, Prucha I, Raciborski R (2015) Sppack: Stata module for cross-section spatial-autoregressive models

Dubé J, Legros D, Thanos S (2016) Putting time into space: establishing the temporal coherence of spatial applications in the housing market. Reg Sci Urban Econ 58:42

Edwards SF, Gable FJ (1991) Estimating the value of beach recreation from property values: an exploration with comparisons to nourishment costs. Ocean Shorel Manag 15(1):37-55

Gopalakrishnan S, Smith MD, Slott JM, Murray AB (2011) The value of disappearing beaches: a hedonic pricing model with endogenous beach width. J Environ Econ Manag 61(3):297-310

Griggs GB (2005) The impacts of coastal armoring. Shore Beach 73(1):13-22

Griggs GB (2009) The effects of armoring shorelines - the California experience. Puget sound shorelines and the impacts of armoring. In: Proceedings of a state of the science workshop, pp 77-84

Griggs GB, Savoy LE (1985) Living with the California coast. Duke University Press, Durham

Griggs GB, Tait JF (1988) The effects of coastal protection structures on beaches along northern Monterey Bay, California. J Coast Res 93-111

Hall MJ, Young RS, Thieler ER, Priddy RD, Pilkey OH Jr (1990) Shoreline response to hurricane Hugo. J Coast Res 6:211-221

Kriesel W, Friedman R (2002) Coastal hazards and economic externality: implications for beach management policies in the American South East. Discussion paper, The H. John Heinz III Center for Science, Economics, and Management

Kriesel W, Friedman R (2003) Coping with coastal erosion: evidence for community-wide impacts. Shore Beach 71(3):19-23

Kriesel W, Randall A, Lichtkoppler F (1993) Estimating the benefits of shore erosion protection in Ohio's Lake Erie housing market. Water Resour Res 29(4):795-801

Kriesel W, Landry CE, Keeler A (2005) Coastal erosion management from a community economics perspective: the feasibility and efficiency of user fees. J Agric Appl Econ 37(2):451-461

Landry CE, Hindsley P (2011) Valuing beach quality with hedonic property models. Land Econ 87(1):92-108

Landry CE, Keeler AG, Kriesel W (2003) An economic evaluation of beach erosion management alternatives. Mar Resour Econ 18(2):105-127

Moran PA (1950) Notes on continuous stochastic phenomena. Biometrika 37(1/2):17-23

Parsons GR (1990) Hedonic prices and public goods: an argument for weighting locational attributes in hedonic regressions by lot size. J Urban Econ 27(3):308-321

Parsons GR, Powell M (2001) Measuring the cost of beach retreat. Coast Manag 29(2):91-103

Parsons GR, Wu Y (1991) The opportunity cost of coastal land-use controls: an empirical analysis. Land Econ 67(3):308-316

Pendleton L, Mohn C, Vaughn RK, King P, Zoulas JG (2012) Size matters: the economic value of beach erosion and nourishment in Southern California. Contemp Econ Policy 30(2):223-237

Pisati M (2001) sg162: Tools for spatial data analysis. Stata Tech Bull 60:21-37

Pompe JJ (1999) Establishing fees for beach protection: paying for a public good. Coast Manag 27(1):57-67

Pompe J (2008) The effect of a gated community on property and beach amenity valuation. Land Econ 84(3):423-433

Pompe JJ, Rinehart JR (1995) Beach quality and the enhancement of recreational property values. J Leis Res 27(2):143-154

Smith TE (2009) Estimation bias in spatial models with strongly connected weight matrices. Geogr Anal 41(3):307-332 
Taylor LO (2003) A primer on nonmarket valuation. The economics of non-market goods and resources. In: Champ P, Boyle K, Brown TC (eds) The hedonic method, vol 3. Springer, Dordrecht, pp 331-393

Wu S-Y, Yarnal B, Fisher A (2002) Vulnerability of coastal communities to sea-level rise: a case study of Cape May County, New Jersey, USA. Clim Res 22(3):255-270

Publisher's Note Springer Nature remains neutral with regard to jurisdictional claims in published maps and institutional affiliations. 